\title{
Influence of novel implant selective laser melting (SLM) framework design on mechanical durability of acrylic veneer
}

\author{
Abbreviated title: SLM framework design effect on acrylic veneer \\ Jaafar Abduo, BDS, DClinDent, PhD, MRACDS (Pros) \\ Senior Lecturer in Prosthodontics, Convenor of Postgraduate Diploma in Clinical Dentistry \\ (Implants) \\ Melbourne Dental School, Melbourne University, 720 Swanston Street, Melbourne, Victoria \\ 3010
}

Michael Curtis, BDSc, PgradDipCD

Former Postgraduate Student

Melbourne Dental School, Melbourne University, 720 Swanston Street, Melbourne, Victoria 3010

Vandana Budhwar, BDS, PgradDipCD

Former Postgraduate Student

Melbourne Dental School, Melbourne University, 720 Swanston Street, Melbourne, Victoria 3010

Joseph Palamara, Dip Ed, PhD,

Associate Professor in Dental Materials

Melbourne Dental School, Melbourne University, 720 Swanston Street, Melbourne, Victoria 3010

Corresponding Author: Dr Jaafar Abduo, Melbourne Dental School, Melbourne University, 720 Swanston Street, Melbourne, Victoria 3010

Phone: +61 390358998

Fax: $\quad+61393411599$

Email address: jaafar.abduo@unimelb.edu.au

The authors have no conflict of interest.

Key words: clinical study, CAD/CAM, titanium, abutment

This is the author manuscript accepted for publication and has undergone full peer review but has not been through the copyediting, typesetting, pagination and proofreading process, which may lead to differences between this version and the Version of Record. Please cite this article as doi: $10.1111 /$ cid.12685

This article is protected by copyright. All rights reserved. 


\section{Authors' contribution}

Jaafar Abduo

- Study design

- Data analysis and interpretation

- Manuscript outline

- Re-writing and critical revision of the article

- Approval of article

- Agreement to be accountable for all aspects of the work in ensuring that questions related to the accuracy or integrity of any parts of the work are appropriately investigated and resolved

\section{Michael Curtis}

- Data collection

- Data analysis and interpretation

- Writing the $1^{\text {st }}$ manuscript draft (methodology and results)

- Approval of article

- Agreement to be accountable for all aspects of the work in ensuring that questions related to the accuracy or integrity of any parts of the work are appropriately investigated and resolved

\section{Vandana Budhwar}

- Data collection

- Data analysis and statistics

- Writing the $1^{\text {st }}$ manuscript draft (introduction and discussion)

- Approval of article

- Agreement to be accountable for all aspects of the work in ensuring that questions related to the accuracy or integrity of any parts of the work are appropriately investigated and resolved

Joseph Palamara

- Study design

- Mechanical data interpretation

- Critical revision of the article

- Approval of article

- Agreement to be accountable for all aspects of the work in ensuring that questions related to the accuracy or integrity of any parts of the work are appropriately investigated and resolved 


\section{Abstract}

Background: A novel implant framework design is proposed to improve the mechanical durability of acrylic veneer.

Purposes: Comparing the mechanical durability of acrylic veneer on implant frameworks fabricated from selective laser melting (SLM) with novel design against conventional computer numeric controlled (CNC) milled frameworks.

Materials and methods: Implant titanium frameworks with distal cantilever were fabricated by SLM $(n=10)$ and CNC milling $(n=10)$. The CNC frameworks had multiple vertical pins, while the SLM frameworks had 3D metal networks of horizontal beams connected by vertical struts. All the frameworks were veneered with acrylic teeth and resin material and were subjected to a static load-to-failure test at the cantilever region. The load-to-failure readings and the pattern of prosthesis damage were recorded for each prosthesis.

Results: The CNC and SLM prostheses failed at statistically similar loads. The acrylic veneer around the $\mathrm{CNC}$ frameworks tend to initially crack around the distal implant followed by acrylic chipping. Six SLM prostheses failed at the framework connector on the mesial implant by separation of the screw seat. After reloading these prostheses, they failed by acrylic veneer chipping. The SLM prostheses had significantly less incidence of acrylic flexure and severity of acrylic veneer chipping than CNC prostheses.

This article is protected by copyright. All rights reserved. 
Conclusions: The SLM framework with novel design is efficient in reinforcing acrylic veneering. However, the SLM frameworks appeared weak in thin sections, such as the screw seat.

\section{KEYWORDS}

additive manufacturing, milling, titanium, fracture resistance

\section{INTRODUCTION}

In the last few decades, oral implants have been proven to be a successful treatment to replace missing teeth. Evidence has shown outstanding success and subsequent improvement in quality of life. ${ }^{1,2}$ One of the popular long span implant prostheses is the fixed hybrid prosthesis, where a metal framework is fabricated and veneered by artificial teeth and acrylic resin. ${ }^{1-3}$ This concept has the advantages of ease of fabrication, versatility, and ability to restore missing teeth and associated tissues. ${ }^{4}$ However, despite the steady advances in manufacturing as well as technical procedures, a significant percentage of patients reported complications with this treatment modality. The most frequently observed mechanical complication is fracture of veneering material, which may occur in $20 \%$ of cases. ${ }^{5,6}$ This complication affects the function, aesthetic and patient comfort, and the whole prosthesis may eventually require replacement. In addition, substantial clinical and technical time will be consumed in managing veneering material fracture. Further, chronic veneer complications are associated with considerable inconvenience and financial burden on implant patients.

Due to the brittle nature and the susceptibility of acrylic veneer material to fracture, it is frequently reinforced with a rigid metal framework. ${ }^{7-12}$ Incorporation of metal wires and 
beams were confirmed to reduce deflection and increase fracture resistance and toughness of acrylic resin. ${ }^{9}$ Likewise, The implant prosthesis metal framework is thought to play a significant role on the durability of the prosthesis and the veneering material. ${ }^{13}$ Specifically, it is needed for acrylic reinforcement, reduce the bulk of framework and allow for cleansability of the prostheses. ${ }^{3,4,13}$ This is more important in high stress regions such as cantilevers where the acrylic veneer will be subjected to heavy tensile stresses. ${ }^{3,14,15}$ On the other hand, several authors indicated that the efficiency of metal reinforcement is dependent on the thickness, the rigidity, the position of the metal structure and the design of the retentive features. $^{7-9,16}$

Early frameworks were produced by casting noble and base metal alloys. ${ }^{3,4}$ In order to retain the veneering materials, mechanical features, such as pins, grooves and beads, are incorporated to enhance the embedment and retention of acrylic resin material. ${ }^{3,4,17}$ More recently, frameworks are produced by computer-aided design and computer numeric controlled ( $\mathrm{CNC}$ ) milling. In this method, the frameworks are digitally designed and fabricated from milling commercially pure titanium, titanium alloy or base-metal alloy. The perceived advantages of this method of fabrication are precise production, durability, reduced fabrication cost and ease of framework customization. ${ }^{18,19}$ The clinical studies have proven that this method provides a clinical outcome similar to cast frameworks. ${ }^{19,20}$ One of the limitations of this method is the influence of milling tools on framework design. For example, deep retentive features on the external surface of the framework cannot be incorporated with milling due to cutting bur dimensions. ${ }^{18}$

Recently, additive manufacturing became an alternative method for framework fabrication. ${ }^{18,21}$ This is defined as the process of joining materials to make objects layer upon layer. Metal frameworks can be produced via the process of selective laser melting (SLM) 
where, a laser beam is applied on a pool of metal powder to selectively melt and connect the powder particles. The process is repeated in multiple layers until the whole framework is produced. ${ }^{18,21,22}$ SLM uniqueness lies in its ability to produce highly customized workpieces without being time consuming or labour intensive. ${ }^{18,21}$ Additional advantages include minimal material wastage, passive production without force application and potentially enhanced precision. ${ }^{18,22,23}$ Recent research indicates improvements of metal objects produced by SLM. ${ }^{22,24,25}$ Currently, SLM is used by several laboratories to produce crown copings, removable partial frameworks and implants. ${ }^{26-30}$ However, there is very limited literature on the use of this method for implant prosthesis fabrication. This research proposes and investigates a novel implant SLM framework design that is distinguished by a complex 3D metal network that enhances resin infiltration. The metal network is composed of horizontal beams crossing the whole length of the framework and connected by vertical struts. The potential advantages of resin infiltration of the complex metal network is increasing the durability and fracture resistance of acrylic veneer, ${ }^{7,8}$ and reducing the incidence of mechanical complications. In addition, the complex metal network is thought to eliminate the localised areas of stress concentration associated with traditional retentive features. Therefore, the aims are to introduce a novel implant SLM framework design, and to compare the mechanical durability of acrylic veneer on implant SLM frameworks with novel 3D metal network against conventional CNC frameworks. In order to challenge the prostheses, a distal cantilever was incorporated. As a result, the loaded prostheses are expected to flex at the cantilever region. The prostheses were tested using the static load-to-failure protocol. The null hypothesis is the veneering materials on SLM and CNC frameworks will have comparable load-to-failure.

This article is protected by copyright. All rights reserved. 


\section{MATERIALS AND METHODS}

\subsection{Prostheses fabrication}

The evaluated prosthesis design was a 5-unit prosthesis extending from the maxillary second incisor to the first molar. The prosthesis framework was $35 \mathrm{~mm}$ long and fits on external hex Branemark implants with $4.0 \mathrm{~mm}$ diameter. The implants were located in the maxillary canine and second premolar positions and they were $15 \mathrm{~mm}$ apart from their centres. A distal cantilever of $10 \mathrm{~mm}$ was incorporated to replace the first molar.

The CNC and the SLM frameworks were designed digitally by the same centre (Osteon Medical, Melbourne, Australia) and they exhibited similar dimensions and designs except for the resin retention features. A minimum thickness of $3 \mathrm{~mm}$ for the body of the frameworks was applied to ensure mechanical durability. ${ }^{3}$ The CNC frameworks were produced from grade 5 commercially pure titanium by a milling centre (Osteon Medical, Melbourne, Australia). Five vertical pins were incorporated with the CNC frameworks design in order to retain the acrylic veneer (Figure $1 \mathrm{~A}$ ).

The SLM frameworks were fabricated from grade 5 titanium by an industrial research facility (Commonwealth Scientific and Industrial Research Organization, Melbourne, Australia). Fine metal powder particles were locally fused by a $400 \mathrm{~W}$ diode pumped ytterbium fibre laser. The frameworks were built up in layers which were $50 \mu \mathrm{m}$ thick by lowering the build platform within the SLM machine. The SLM frameworks were then heat treated under negative pressure to strengthen the metal structure. Once post-processing sintering was completed, the SLM frameworks were sent to the milling centre (Osteon Medical) where the implant connection seats were refined by milling the frameworks to similar finish of CNC frameworks. The design of the SLM frameworks included 3D metal 
network in the form of 2 horizontal beams of $2 \mathrm{~mm}$ thickness in both sides of the framework connected via vertical struts along the whole span of the framework (Figure 1B). For each group, 10 frameworks were produced.

All the frameworks were veneered by acrylic teeth (Trubyte IPN acrylic teeth, Dentsply, Pennsylvania, USA) and acrylic resin by a single experienced dental technician. A wax set-up of the acrylic teeth was completed on one framework and a silicone putty key on the outer surface was constructed and used to ensure consistency in teeth set-ups on every framework. The surface of all the frameworks was treated by an opaque bonding agent (Super Bond C\&B, Sun Medical CO LTD, Shiga, Japan). The waxed prostheses were flasked and heat-cured acrylic resin (Rapid Simplified, Vertex Dental, Soesterberg, The Netherlands) was used to process the prostheses. After curing the acrylic resin, the prostheses were cleaned and polished (Figure 2).

\subsection{Mechanical testing and data collection}

A solid square brass jig was designed and machined to secure the frameworks. The brass jig had dimensions of $100 \mathrm{~mm}$ in length and width, and $40 \mathrm{~mm}$ height. Two vertical holes were machined in the jig that correspond to implants locations to allow for close fitting of Branemark implant analogues. The analogues were secured in the jig by lateral screws. This allowed the analogues to be changed after testing each prosthesis. The prosthesis was fitted to the implant analogues and the retaining screws (RP Clinical Screw, Nobel Biocare AB,

This article is protected by copyright. All rights reserved. 
Göteborg, Sweden) were torqued to $35 \mathrm{Ncm}$ utilizing a Nobel Biocare torque wrench (Nobel Biocare AB; Göteborg, Sweden). The prostheses were randomly selected for testing.

Once secured on the jig, each prosthesis was loaded on the cantilever region by a static load-to-failure with a materials load testing machine (MTS 810 Material Test System, MTS Systems Corporation, MN, USA). The prostheses were loaded until failure that is detected by a sudden drop in load. To represent an opposing tooth cusp, a perpendicular load was applied on the mesial fossa of the molar by $8 \mathrm{~mm}$ diameter round-ended loading rod. The load was applied at a crosshead speed of $1 \mathrm{~mm} / \mathrm{min}$. The load-to-failure in Newton (N) was recorded as soon as failure of the prosthesis occurred determined by a sharp decrease in applied load, triggering the machine interlocks that pause the loading. In addition, the behaviour of the prostheses and any form of damage was reported, and the corresponding load reading was recorded. Since different forms of damage were anticipated for the metal frameworks and the veneering materials, the load-to-failure readings were divided in 2 categories: (1) first point of failure and (2) final point of failure. The first point of failure encompassed the loads when any form of damage was visually detected, yet without leading to a sharp drop of the applied load or shutting the machine interlock. This involved acrylic resin crack lines development, or screw related problems. The final point of failure was indicated by an audible crack and confirmed by a sudden drop in the recorded load-tofailure curve. In addition, the pattern of damage was reported for each prosthesis at the first and final points of failure. The anticipated failures were (1) flexural failure of the veneering resin in the form of crack lines, (2) acrylic teeth chipping and (3) framework failure (Figure 3). The chipping is considered minor if it is confined to the acrylic tooth, and moderate if it involves the veneering resin. Chipping involving metal framework exposure (adhesive failure) is considered major. 


\subsection{Statistical analysis}

The means and standard deviations of the loads at first and final points of failures, and acrylic failure were calculated for each group. In addition, the coefficient of variation (CV) was calculated for each prosthesis group at every point of failure. The Shapiro Wilk test was conducted to confirm the normality of the data. Student's t-tests were conducted to evaluate the difference between the 2 groups for each point of failure. The statistical tests were completed using the SPSS software package (SPSS for Windows, v23; SPSS Inc., Chicago, IL). The data of the first and final points of failure were presented in Box-and-Whisker plots. In addition, the frequency of each pattern of damage was reported for the first and final points of failure. The Chi-square test was implemented to determine the significance of damage pattern between the 2 framework groups. For all statistical tests, the level of significance was set at 0.05 .

\section{RESULTS}

At first point of failure, the CNC prostheses showed signs of failure at an average load of 1352.4 $\mathrm{N}(\mathrm{SD}=307.5 \mathrm{~N})$ and the SLM prostheses showed signs of failure at an average load of 1566.1 N (SD = 771.5 N) (Figure 4A). The SLM prostheses had considerably greater variation $(C V=0.49)$ in the first point of failure than the $C N C$ prostheses $(C V=0.23)$. The difference between the 2 groups was insignificant $(P=.43)$. Nine CNC prostheses exhibited

flexural failure by showing crack lines through the veneering resin of the $2^{\text {nd }}$ premolar that corresponds to the location of the distal implant next to the cantilever. One CNC prosthesis

This article is protected by copyright. All rights reserved. 
had simultaneous moderate chipping of the $1^{\text {st }}$ molar in addition to flexure cracking. On the contrary, 6 SLM prostheses failed at the mesial framework connector on the implant away from the cantilever by separation of the screw seat of the framework cylinder (Figure 5A), which may explain the greater variation of load to failure experienced by the SLM prostheses. The separated screw seats were clearly deformed around the screw head (Figure 5B). One prosthesis showed signs of acrylic flexure cracking around the $2^{\text {nd }}$ premolar and 3 prostheses had minor chipping at or near the point of loading ( $1^{\text {st }}$ molar) in addition to acrylic flexure. The SLM prostheses that failed from the metal cylinders were reattached with long impression pins and reloaded till acrylic failure.

At the final point of failure, the CNC prostheses failed at an average load of $2038.8 \mathrm{~N}$ $(\mathrm{SD}=450.5 \mathrm{~N})$. The SLM prostheses failed at an average load of 2365.6 N $(\mathrm{SD}=298.8 \mathrm{~N})$ (Figure $4 \mathrm{~B})$. The SLM prostheses had less variation $(\mathrm{CV}=0.13)$ than the CNC prostheses $(\mathrm{CV}=0.22)$ at the final point of failure. The difference between the two groups was insignificant $(P=.07)$. In addition to flexure crack developed at the first point of failure, 8 CNC prostheses developed moderate chipping, 1 had minor chipping and 1 had major chipping at the final point of failure. None of the CNC prostheses showed any evidence of metal failure at any point of loading. Interestingly, the SLM prostheses suffered from less severe acrylic failure than the CNC prostheses. Specifically, at the second point of failure, no additional prostheses showed flexure crack at the cantilever region than the 4 prostheses at the first point of failure. A total of 9 SLM prostheses had minor chipping, and the flexure crack was evident only for one of them. The remaining prosthesis suffered from major chipping and flexure crack. No additional metal failure was observed after reloading the SLM prostheses.

This article is protected by copyright. All rights reserved. 
The percentages of each damage pattern at the different points of failure were summarized in Figure 6 . The difference in the pattern was obvious, and the severity of chipping was greater for the CNC prostheses than the SLM prostheses. This was found to be statistically significant for the first point of failure $(P=.02)$ and final point of failure $(P=$ $.001)$.

\section{DISCUSSION}

The present study indicates a comparable outcome of the CNC and SLM prostheses at the first and final points of failure. However, the SLM prostheses have clear advantage of being more resistant to acrylic veneer flexure cracks and suffering from less severe chipping than CNC prostheses. Clinically, this means less severe complications and easier management of acrylic fracture. This can be attributed to the complex 3D network framework design which has been produced by additive manufacturing. ${ }^{18,21}$ Thus, the hypothesis that veneering materials on SLM and CNC frameworks will have comparable load-to-failure is rejected. On the other hand, the SLM frameworks were vulnerable to metal failure and further refinements are needed prior to the clinical application. Thus, this early study is important in outlining the potential advantages and limitations of these new frameworks.

The low incidence of acrylic veneer flexure crack at the cantilever region for the SLM group in comparison to the CNC group can be due to the resistance of metal structures to flexural deformation and the infiltration of the acrylic resin material within the metal structure network. The bulk of the metal through the whole length of the SLM framework appeared sufficient to resist deformation of the cantilevered segment, which reduces the stresses within the veneering acrylic. The rigidity of SLM framework was achieved by the 
incorporation of multiple horizontal beams of sufficient thickness in the lingual and buccal aspects. More importantly, the infiltration of the acrylic resin material within the SLM metal structure forms an interdigitated composite of metal and acrylic, which will eventually lead to an increase in mechanical rigidity, flexural strength and fracture resistance of the acrylic veneer, and reduction of catastrophic crack propagation along the interface. ${ }^{14,31}$ Although, this is the first study to evaluate the durability of implant prostheses fabricated with this framework design, it endorses earlier studies on acrylic resin reinforcement with metallic structure $^{7-12}$ For example, the metal beams of the SLM frameworks were perpendicular to the applied loads. Such orientation was found by the acrylic reinforcement studies to be the most superior in improving acrylic fracture resistance..$^{8,16}$ Specifically, this arrangement is advantageous in regions of high stress ${ }^{23}$ like prosthesis cantilever, ${ }^{14,31}$ where the beams crossed the whole framework length including the distal implant cylinder. A potential additional advantage of the SLM frameworks is the roughened surface that was generated through the additive fabrication procedure. Earlier studies reported rough metal surfaces were associated with increased surface area and enhanced the mechanical bonding between the acrylic material and the framework, which can further contribute to enhanced fracture resistance ${ }^{8,12}$ and gradual transfer of stresses at the interface. However, the level of roughness of SLM frameworks and its actual contribution to acrylic reinforcement have to be evaluated by additional laboratory studies.

On the contrary, the CNC prosthesis acrylic exhibited greater flexural fracture which indicates less acrylic support and greater flexural deformation. This may be due to elastic deformation of the metal framework on loading. However, it is more likely related to greater acrylic bulk and less acrylic infiltration of the CNC frameworks in comparison to the SLM frameworks, which have made the acrylic material on the CNC frameworks more prone to 
deformation and fracture. ${ }^{31}$ This was noticeable at the cantilever region where all the CNC frameworks showed acrylic resin flexure cracks. In addition, while the presence of multiple vertical pins in the CNC frameworks is necessary to retain the acrylic resin, they may create stress concentration spots within the acrylic resin during loading. ${ }^{7,9}$ Moreover, contrary to the SLM frameworks, the smooth surface of the CNC frameworks may reduce the mechanical adhesion with the resin. Nevertheless, the clinical impact of this difference is yet to be determined, since the acrylic veneer fractured at a load that is much higher than the maximal masticatory forces which tend to be in the range of $300-600 \mathrm{~N}^{32,33}$ However, the clinical fatigue effects of the prothesis during functional simulation have not been considered in the present study.

Since no SLM framework had metal failure at the cantilever region, this study may suggest that the additive manufacturing technology is capable of producing durable prosthesis frameworks. ${ }^{24,25,30}$ This is consistent with the few clinical studies on SLM removable partial dentures and single crowns that indicated SLM is a viable method of producing metal without failure related to the SLM manufacturing. ${ }^{26-29}$ However, the obvious limitation of SLM frameworks that was disclosed in the present study is the metal failure at the screw base that had occurred in 6 frameworks, where the metal under the screw head was separated from the framework mesial cylinder due to opposing stress to the cantilever forces. This problem can be due to the quality of the SLM metal at the thin sections, the minimal thickness of framework metal under the screw head, and the retained stresses induced within the framework after tightening the screws. SLM manufacturing of metal frameworks involves layered production by repeated laser melting of metal particles. The laser beam aims to liquidize solely the external surface of the particles by raising the temperature closer to the melting temperature to avoid melting the particles core. ${ }^{30,34,35}$ As 
the external surface is liquidised, it will flow within the spaces between the particles. However, after the solidification of the melted material, some microporosity may remain..$^{30,34,35}$ While the more recent papers indicated significant reduction of porosity of SLM-produced workpieces, ${ }^{24,25}$ it is possible that thin sections are more difficult to produce by SLM and minimal porosity may influence the durability of thin metal sections. Gehrke et al reported anisotropy within implants produced by SLM, where the external surface had greater porosity in comparison to the core of the implants. ${ }^{30}$ After fracturing the implants, the metal layers failed with ductile appearance ${ }^{30}$ which is similar to the separated framework segment of the present study (Figure 5). Therefore, it can be speculated that at thin sections the SLM frameworks are weaker than the CNC frameworks. The impact of weaker material in thin section is further exacerbated by post-processing milling of the fitting surfaces. This step was necessary, as the SLM external surfaces exhibit inherent coarseness and stepped roughness. ${ }^{18,22,36}$ This surface will affect the fit of framework and may damage the underlying implant unless it is refined by machining. While the clinical impact of the weakness of the thin cylinder sections is difficult to confirm, the present concept of SLM framework fabrication can be further modified to ensure durability of the material at the screw junction. For example, a thicker cylinder base and longer screw can be produced to prevent framework mechanical failure.

Although this study supports the validity of SLM frameworks, more investigations are needed to ensure it fulfils implant framework requirements such as allowance for teeth placement and ensuring aesthetic appearance. ${ }^{3,8}$ Despite the benefits of the evaluated 3D network design, it may not be applicable to every clinical scenario. Patients with limited vertical space and limited ridge resorption may not have sufficient room for teeth setting on the metal network. Further, the network may leave the acrylic resin thin leading to aesthetic 
problems. $^{3,8}$ Since our model is a simplified setup for testing fracture force, it can be expected that further testing under cyclic loading and thermocycling of the frameworks will provide information on how well these prostheses perform in an intraoral environment.

\section{CONCLUSIONS}

Within the limitations of this study, it can be concluded that SLM is a promising technology to produce enhanced design of implant frameworks. In comparison to CNC frameworks, implant frameworks with 3D networks that can only be produced by SLM appears efficient in reinforcing acrylic veneer. The SLM frameworks suffer from weakness at thin sections that are subjected to stress such as at the screw junction. This problem has to be resolved prior to clinical application.

\section{ACKNOWLEDGEMENTS}

The authors acknowledge the generous support from Osteon Medical and the technical advice from Mr Michael Tuckman. The authors would like to thank Mr Attila Gergely for his technical work in veneering the frameworks. The study was supported by Melbourne Dental School Research Higher Degree Funding and internal funds from the Restorative Section of Melbourne Dental School.

\section{CONFLICT OF INTEREST}

The authors declare no conflict of interest.

This article is protected by copyright. All rights reserved. 


\section{REFERENCES}

[1] Zarb GA, Schmitt A. The longitudinal clinical effectiveness of osseointegrated dental implants: the Toronto Study. Part II: The prosthetic results. J Prosthet Dent. 1990;64(1):53-61.

[2] Zarb GA, Schmitt A. Implant prosthodontic treatment options for the edentulous patient. J Oral Rehabil. 1995;22(8):661-671.

[3] Drago C, Howell K. Concepts for designing and fabricating metal implant frameworks for hybrid implant prostheses. J Prosthodont. 2012;21(5):413-424.

[4] Mericske-Stern R. Prosthetic considerations. Aust Dent J. 2008;53(Suppl 1):49-59.

[5] Goodacre CJ, Bernal G, Rungcharassaeng K, Kan JY. Clinical complications with implants and implant prostheses. J Prosthet Dent. 2003;90(2):121-132.

[6] Salvi GE, Bragger U. Mechanical and technical risks in implant therapy. Int J Oral Maxillofac Implants. 2009;24(Suppl):69-85.

[7] Jagger DC, Harrison A, Jandt KD. The reinforcement of dentures. J Oral Rehabil. 1999;26(3):185194.

[8] Takahashi T, Gonda T, Maeda Y. The influence of reinforcement on strain in maxillary complete dentures: a preliminary report. Int J Prosthodont. 2011;24(3):273-276.

[9] Polyzois GL, Tarantili PA, Frangou MJ, Andreopoulos AG. Fracture force, deflection at fracture, and toughness of repaired denture resin subjected to microwave polymerization or reinforced with wire or glass fiber. J Prosthet Dent. 2001;86(6):613-619.

[10]Balch JH, Smith PD, Marin MA, Cagna DR. Reinforcement of a mandibular complete denture with internal metal framework. J Prosthet Dent. 2013;109(3):202-205.

This article is protected by copyright. All rights reserved. 
[11]Rodrigues AH. Metal reinforcement for implant-supported mandibular overdentures. J Prosthet Dent. 2000;83(5):511-513.

[12]Fahmy NZ, Sharawi A. Effect of two methods of reinforcement on the fracture strength of interim fixed partial dentures. J Prosthodont. 2009;18(6):512-520.

[13]Menini $M$, Pesce $P$, Bevilacqua $M$, et al. Effect of Framework in an Implant-Supported Full-Arch Fixed Prosthesis: 3D Finite Element Analysis. Int J Prosthodont. 2015;28(6):627-630.

[14]Falk H, Laurell L, Lundgren D. Occlusal force pattern in dentitions with mandibular implantsupported fixed cantilever prostheses occluded with complete dentures. Int J Oral Maxillofac Implants. 1989;4(1):55-62.

[15]Davis DM, Packer ME, Watson RM. Maintenance requirements of implant-supported fixed prostheses opposed by implant-supported fixed prostheses, natural teeth, or complete dentures: a 5-year retrospective study. Int J Prosthodont. 2003;16(5):521-523.

[16]Ruffino AR. Effect of steel strengtheners on fracture resistance of the acrylic resin complete denture base. J Prosthet Dent. 1985;54(1):75-78.

[17]Taylor TD, Belser U, Mericske-Stern R. Prosthodontic considerations. Clin Oral Implants Res. 2000;11(Suppl 1):101-107.

[18]Abduo J, Lyons K, Bennamoun M. Trends in computer-aided manufacturing in prosthodontics: a review of the available streams. Int J Dent. 2014;783948.

[19]Kapos T, Ashy LM, Gallucci GO, et al. Computer-aided design and computer-assisted manufacturing in prosthetic implant dentistry. Int J Oral Maxillofac Implants. 2009;24 (Suppl):110-117.

[20]Ortorp A, Jemt T. CNC-milled titanium frameworks supported by implants in the edentulous jaw: a 10-year comparative clinical study. Clin Implant Dent Relat Res. 2012;14(1):88-99.

This article is protected by copyright. All rights reserved. 
[21]van Noort R. The future of dental devices is digital. Dent Mater. 2012;28(1):3-12.

[22]Barazanchi A, Li KC, Al-Amleh B, et al. Additive Technology: Update on Current Materials and Applications in Dentistry. J Prosthodont. 2017;26(2):156-163.

[23]Ortorp A, Jonsson D, Mouhsen A, Vult von Steyern P. The fit of cobalt-chromium three-unit fixed dental prostheses fabricated with four different techniques: a comparative in vitro study. Dent Mater. 2011;27(4):356-363.

[24]Koutsoukis T, Zinelis S, Eliades G, et al. Selective Laser Melting Technique of Co-Cr Dental Alloys: A Review of Structure and Properties and Comparative Analysis with Other Available Techniques. J Prosthodont. 2015;24(4):303-312.

[25]Alageel O, Abdallah MN, Alsheghri A, et al. Removable partial denture alloys processed by lasersintering technique. J Biomed Mater Res B Appl Biomater. 2018;106(3):1174-1185.

[26]Almufleh B, Emami E, Alageel O, et al. Patient satisfaction with laser-sintered removable partial dentures: A crossover pilot clinical trial. J Prosthet Dent. 2018;119(4):560-567.

[27]Williams RJ, Bibb R, Eggbeer D, Collis J. Use of CAD/CAM technology to fabricate a removable partial denture framework. J Prosthet Dent. 2006;96(2):96-99.

[28]Abou Tara M, Eschbach S, Bohlsen F, Kern M. Clinical outcome of metal-ceramic crowns fabricated with laser-sintering technology. Int J Prosthodont. 2011;24(1):46-48.

[29]Ye H, Ning J, Li M, et al. Preliminary Clinical Application of Removable Partial Denture Frameworks Fabricated Using Computer-Aided Design and Rapid Prototyping Techniques. Int J Prosthodont. 2017;30(4):348-353.

[30]Gehrke SA, Perez-Diaz L, Dedavid BA. Quasi-static strength and fractography analysis of two dental implants manufactured by direct metal laser sintering. Clin Implant Dent Relat Res. 2018;20(3):368-374.

This article is protected by copyright. All rights reserved. 
[31]von Gonten AS, Medina T, Jr., Woolsey GD, Hill DR. Modifications in the design and fabrication of mandibular osseointegrated fixed prostheses frameworks. J Prosthodont. 1995;4(2):82-89.

[32]van der Bilt A, Tekamp A, van der Glas H, Abbink J. Bite force and electromyograpy during maximum unilateral and bilateral clenching. Eur J Oral Sci. 2008;116(3):217-222.

[33]Carr AB, Laney WR. Maximum occlusal force levels in patients with osseointegrated oral implant prostheses and patients with complete dentures. Int J Oral Maxillofac Implants. 1987;2(2):101108.

[34]Kathuria YP. Microstructuring by selective laser sintering of metallic powder. Surf Coat Tech. 1999;116-119:643-647.

[35]Khaing MW, Fuh JYH, Lu L. Direct metal laser sintering for rapid tooling: processing and characterisation of EOS parts. J Mater Process Tech. 2001;113(1-3):269-272.

[36]Fernandez M, Delgado L, Molmeneu M, et al. Analysis of the misfit of dental implant-supported prostheses made with three manufacturing processes. J Prosthet Dent. 2014;111(2):116-123.

\section{Figure legend}

FIGURE 1 The framework designs evaluated in the study. A, CNC framework with the 5 vertical pins. B, SLM framework with complex 3D metal network showing 2 horizontal beams on each side connected by multiple small vertical struts

FIGURE 2 Examples of processed prostheses. A, CNC prosthesis. B, SLM prosthesis. The two framework groups received similar teeth set-ups

This article is protected by copyright. All rights reserved. 
FIGURE 3 Examples of failure of acrylic veneering materials. A, Acrylic tooth fracture. B, Flexure crack of the acrylic veneer around the distal implant $\left(2^{\text {nd }}\right.$ premolar $)$ in addition to acrylic tooth fracture $\left(1^{\text {st }}\right.$ molar $)$

FIGURE 4 Box-and-Whisker plots of the loads at different load-to-failure readings $(\mathrm{N})$ for the CNC $(n=10)$ and SLM prostheses $(n=10)$. A, First point of failure. B, Final point of failure

FIGURE 5 A, Example of failed framework connector on mounting jig. B, Separation of screw seat from the framework cylinder on the mesial implant. The separated segment appears thin and deformed

FIGURE 6 The percentages of each failure pattern for CNC $(n=10)$ and SLM $(n=10)$ prostheses at the first point of failure and final point of failure

This article is protected by copyright. All rights reserved. 


\section{University Library}

\section{- M M N E R VA A gateway to Melbourne's research publications}

Minerva Access is the Institutional Repository of The University of Melbourne

Author/s:

Abduo, J;Curtis, M;Budhwar, V;Palamara, J

Title:

Influence of novel implant selective laser melting framework design on mechanical durability of acrylic veneer

Date:

2018-12-01

\section{Citation:}

Abduo, J., Curtis, M., Budhwar, V. \& Palamara, J. (2018). Influence of novel implant selective laser melting framework design on mechanical durability of acrylic veneer. CLINICAL IMPLANT DENTISTRY AND RELATED RESEARCH, 20 (6), pp.969-975. https:// doi.org/10.1111/cid.12685.

Persistent Link:

http://hdl.handle.net/11343/284669 